\title{
Acid transport by intracellular vesicles
}

\author{
R. W. VAN DYKE \\ From the Division of Gastroenterology and Department of Medicine, University of Michigan Medical \\ Center, Ann Arbor. Michigan. USA
}

\begin{abstract}
Van Dyke RW (Division of Gastroenterology and Department of Medicine. University of Michigan Medical Center. Ann Arbor. Michigan. USA). Acid transport by intracellular vesicles. Journal of Internal Medicine 1990: 228, Suppl. 1: 41-46.

Many intracellular organelles contain a unique primary, electrogenic proton pump termed the vacuolar $\mathrm{H}^{+}$-ATPase. This pump, found in many endocytic, secretory, and storage vesicles in fungal, plant and animal cells, functions, in conjunction with a chloride conductance, to acidify the vesicle interior. Although remotely related to the mitochondrial ATP synthase, the vacuolar $\mathrm{H}^{+}$-ATPase is a distinct pump which differs in inhibitor sensitivity, subunit composition and function. The vacuolar $\mathrm{H}^{+}$-ATPase transports only protons, and permeable anions (chloride) are required for optimal vesicle acidification. Allosteric and regulatory effects are not yet fully understood. Vesicle acidification appears to be essential for receptor-mediated endocytosis, protein synthesis. and secretion and storage of small solutes such as neurotransmitters. A similar plasma membrane-located $\mathrm{H}^{+}$-ATPase may contribute to urinary acidification and cell $\mathrm{pH}$ regulation.
\end{abstract}

Keywords: acidification, endosome, $\mathrm{H}^{+}$-ATPase.

\section{Introduction}

Intracellular vesicles capable of acid-base transport fall into two general categories: (a) relatively stable intracellular organelles, such as endosomes and mitochondria that possess $\mathrm{H}^{+} / \mathrm{OH}^{-}$transporters; and (b) vesicles containing acid-base transporters ultimately destined for insertion into cell plasma membranes. This paper will focus on the former category, and will specifically review the now wellrecognized acidification mechanism of endosomes and other non-mitochondrial organelles. In contrast. these is little information on base transport by vesicles and this topic will not be discussed further.

A variety of intracellular vesicles in many, if not all. eukaryotic cells are acidified: endosomes. lysosomes, Golgi vesicles, secretory granules involved in the regulated secretion of proteins, polypeptide hormones and neurotransmitters, and storage vacuoles in plants and fungi [1-5]. The mechanism of acidification in these diverse organelles appears to

Abbreviations: $\mathrm{NBD}-\mathrm{Cl}=$ 7-chloro-4-nitrobenz-2-oxa-1.3-diazole. DCCD $=$ dicyclohexylcarbodiimide. be a primary electrogenic proton pump, termed the vacuolar $\mathrm{H}^{+}$-ATPase. A similar, if not identical, proton pump is also found on the plasma membrane of certain proton-transporting epithelia, such as the amphibian urinary bladder [6], renal tubular cells [7], and osteoclasts.

\section{$\mathbf{H}^{+}$-ATPase characteristics}

The acidification mechanism in these vesicles has been studied most completely in isolated endosomes [8-13]. lysosomes [14, 15], and adrenal chromaffin granules [16]. Proton transport (assessed using fluorescent $\mathrm{pH}$-sensitive dyes or radiolabelled weak bases) is ATP-dependent, requires $\mathrm{Mg}^{2+}$ (or $\mathrm{Mn}^{2+}$ ). and is poorly supported by other high-energy phosphates [8-13, 17]. Acidification is not directly coupled to movement of any other ion, does not require any specific monovalent cation (unlike the gastric $\mathrm{H}^{+} / \mathrm{K}^{+}$-ATPase), and displays considerable anion sensitivity [10-12]. For example, chloride supports maximal acidification $\left(K_{\mathrm{m}}\right.$ for $\mathrm{Cl}^{-}$is $\sim 20 \mathrm{mM}$ in rat liver multivesicular bodies (MVB) [12]) followed by $\mathrm{Br}^{-} \gg$ gluconate, $\mathrm{NO}_{3}{ }^{-}>\mathrm{SO}_{4}{ }^{2-}$, 


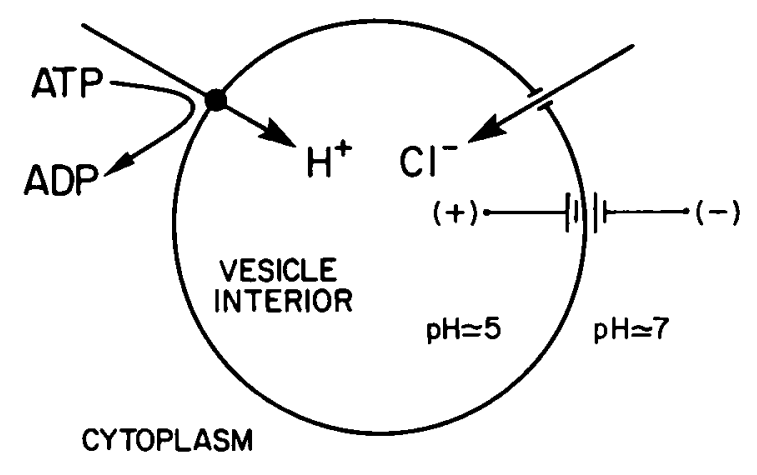

Fig. 1. Model of the vacuolar $\mathrm{H}^{+}$-ATPase in an endosome.

$\mathrm{PO}_{4}{ }^{2-}>$ sucrose [12]. These anion effects may reflect, in part, electrical effects because the $\mathrm{H}^{+}$ATPase is intrinsically electrogenic. This is demonstrated by potential-sensitive fluorescent dyes and radiolabelled anions and by the stimulatory effects of vesicle interior-negative potassium diffusion potentials on vesicle acidification [9-13]. Furthermore, chloride is a relatively permeable anion that collapses the membrane potential developed by the $\mathrm{H}^{+}$-ATPase [12]. Finally, the relative contributions of the $\mathrm{pH}$ $(\Delta \mathrm{pH})$ and potential $(\Delta \psi)$ gradients to the overall electrochemical proton gradient $\left(\Delta \tilde{\mu}_{\mathrm{H}^{+}}\right)$developed by the $\mathrm{H}^{+}$-ATPase are inversely related and can be varied by altering the medium chloride concentration or by potassium diffusion potentials $[12,13,18]$ (Fig. 1).

As noted above, endocytic vesicles appear to be relatively permeable to chloride, and the presence of a specific chloride conductance or channel in the endosome membrane is suggested by the following observations: (a) addition of chloride rapidly collapses $\Delta \psi$ in endosomes, and (b) chloride is taken up by endosomes in a potential-sensitive manner [12. 19]. Preliminary work using the chloride-sensitive fluorescent dye SPQ has also demonstrated chloride fluxes across the membrane of plant vacuoles [20]. However the characteristics and mechanism of this flux are unknown. This postulated chloride conductance does not appear to be a structural part of the vacuolar $\mathrm{H}^{+}$-ATPase as proton pumps that are solubilized and reconstituted into liposomes do not acidify in the presence of chloride. Instead, the proton pumps develop a large $\Delta \psi$ and acidification in this setting depends on the presence of potassium and valinomycin to shunt charge [21,22].

Charge compensation is not, however, the only mechanism by which anions affect the vacuolar $\mathrm{H}^{+}$-
ATPase and vesicle acidification. Certain observations suggest that some anions may have additional stimulatory (chloride) or inhibitory (nitrate) allosteric effects: (a) some, but not all. investigators have reported that isolated, solubilized plant and chromaffin granule $\mathrm{H}^{+}$-ATPases are stimulated by $\mathrm{Cl}^{-}[3,16,21,22] ;$ (b) $\mathrm{Cl}^{-}$stimulates vesicle acidification to a considerably greater degree than voltage-clamping with potassium and valinomycin $[12,16]$; (c) $\mathrm{NO}_{3}{ }^{-}$, a highly permeable anion, inhibits ATPase activity and acidification, even in the presence of chloride [18] and; (d) $\mathrm{NO}_{3}{ }^{-}$inhibition is, at least in part. attributed to a direct interaction with the proton pump $[16,18,21]$. The site(s) of these anion effects are unknown.

Vesicle acidification is associated with an ATPase activity that displays a neutral $\mathrm{pH}$ optimum and a $K_{\mathrm{m}}$ for ATP of 80-150 $\mu \mathrm{M}[34,16,17]$. The vacuolar $\mathrm{H}^{+}$-ATPase, however, does not have a phosphorylated intermediate. which sets it apart from other well-known cation pumps such as $\mathrm{Na}^{+} / \mathrm{K}^{+}$-ATPase and $\mathrm{H}^{+} / \mathrm{K}^{+}$-ATPase.

Regulation of vesicle acidification is not well understood, but the fact that it may occur is suggested by observations that different endocytic vesicles display different interior $\mathrm{pH}_{\mathrm{i}} \mathrm{s}$ during in-vivo endocytosis. In general, early endosomes are less acidic whereas late endosomes and lysosomes are more acidic. Potential sites of regulation include proton pump density, state of pump coupling, allosteric activation. availability of chloride and changes in chloride conductance, changes in membrane permeability to protons and to other anions or cations, changes in the membrane lipid environment, and the presence or absence of other electrogenic transporters in the same vesicle. Only a few studies in this area have been reported. In one study, early (but not late) endosomes from some cultured cells appeared to contain $\mathrm{Na}^{+} / \mathrm{K}^{+}$-ATPase and vesicle acidification was potentiated by incubation with vanadate $[23,24]$. On the other hand, in three types of purified rat liver endosomes, steady-state ATPdependent $\mathrm{pH}_{1}$ did not vary substantially between populations of endosomes, which suggests that many types of endosomes may ultimately achieve the same $\mathrm{pH}_{\mathrm{i}}$ if sufficient time is allowed after vesicle formation [25]. This remains an interesting area for future exploration. 


\section{$\mathrm{H}^{+}$-ATPase inhibitors}

The vacuolar $\mathrm{H}^{+}$-ATPase is inhibited by a variety of compounds, although no truly specific inhibitor has been identified to date. Inhibitors include $N$ ethylmaleimide (which probably reacts with a critical cysteine residue on the catalytic subunit), 7-chloro4-nitrobenz-2-oxa-1.3-diazole (NBD-Cl) (which probably reacts with a cysteine or tyrosine residue). $\mathrm{NO}_{3}{ }^{-}$(which probably acts directly on the pump but also causes dissociation of the catalytic complex). and dicyclohexylcarbodiimide (DCCD) (which is likely to bind to a glutamic carboxyl group in the membrane-spanning proton channel) [3,26]. The vacuolar $\mathrm{H}^{+}$-ATPase is resistant to vanadate (which inhibits $E_{1}-E_{2}$ cation pumps such as $\mathrm{Na}^{+} / \mathrm{K}^{+}$-ATPase). oligomycin, azide, and efrapeptin (which inhibit the mitochondrial ATP synthase). Although the $\mathrm{H}^{+}$ATPase functions normally in the ATP hydrolytic direction. superimposition of a sufficiently large opposing $A \tilde{\mu}_{\mathrm{H}^{+}}$can cause ATP formation.

\section{Structure and function}

Five types of proton pump have been identified to date, including the electroneutral gastric $\mathrm{H}^{+} / \mathrm{K}^{+}$ATPase, the electrogenic fungal plasma membrane $\mathrm{H}^{+}$-ATPase, the mitochondrial ATP synthase (termed $\mathrm{F}_{0} \mathrm{~F}_{1}$-type), the electrogenic cell membrane $\mathrm{H}^{+}$ATPase of bacteria. and the electrogenic vacuolar $\mathrm{H}^{+}$-ATPase (Table 1) [3, 27]. The first two are related, single-subunit, phosphorylating, vanadate-sensitive cation pumps that use an $E_{1}-E_{2}$ reaction mechanism. The latter three are all large multi-subunit structures that may be derived from a very ancient ancestral bacterial cell membrane $\mathrm{H}^{+}$-ATPase [28]. These five proton pumps can be distinguished functionally on the basis of electrogenicity, ionic dependency, and inhibitor sensitivity, although all of them are inhibited by DCCD (Table 1).

The mechanism of proton transport by the vacuolar $\mathrm{H}^{+}$-ATPase is not well understood. However, it is thought that ATP hydrolysis takes place in a large multi-subunit catalytic region on the cytoplasmic side of the membrane. Protons are then extruded through a transmembrane 'proton channel' to the vesicle interior (or luminal side of the membrane). The pump generates a substantial electrochemical proton gradient $\left(\Delta \tilde{\mu}_{\mathrm{H}^{+}}\right)$which, in the presence of permeable anions such as chloride, is predominantly due to $\triangle \mathrm{pH}$. In isolated turtle urinary bladder, where the $\mathrm{H}^{+}$-ATPase is located on the apical membrane of epithelial cells, a $\Delta \tilde{\mu}_{\mathrm{H}^{+}}$of up to $120 \mathrm{mV}$ has been measured using $\mathrm{pH}$-stat and electrophysiological techniques [29]. Using radiolabelled probes to assess $\Delta \mathrm{pH}$ and $\Delta \psi$, steady-state ATP-dependent $\Delta \tilde{\mu}_{\mathrm{H}^{+}}$of $\sim 118 \mathrm{mV}$ was measured in isolated rat liver MVB, a late-stage endosome [19]. In the presence of $25 \mathrm{mM} \mathrm{Cl}^{-}$, which corresponds to the intracellular $\mathrm{Cl}^{-}$concentration measured in rat hepatocytes in vivo, $\mathrm{MVB}$ exhibited a $\mathrm{pH}_{1}$ of $5.9\left(\mathrm{pH}_{0}=7.3\right)$ and a $\Delta \psi$ of $+9.6 \mathrm{mV}$, with respect to cytoplasm. Similarly. lysosomes have been shown to generate a $\Delta \mathrm{pH}$ of $2-2.5 \mathrm{pH}$ units. These proton gradients (up to two orders of magnitude) are not, however, as large as those generated by the gastric $\mathrm{H}^{+} / \mathrm{K}^{+}$-ATPase, which can approach five orders of magnitude. This difference has not been well studied but might be accounted for, in part, by differences in $\mathrm{H}^{+}$/ATP stoichiometry and in proton leaks through the proton pump or surrounding membrane.

Isolation, purification and structural analysis of the vacuolar $\mathrm{H}^{+}$-ATPase are currently in progress. The pumps from Neurospora and higher plant vacuoles, kidney plasma membranes, adrenal chromaffin granules, and brain clathrin-coated

Table 1. Proton ATPases: characteristics

\begin{tabular}{|c|c|c|c|c|c|}
\hline Type & $\mathrm{H}^{+} / \mathrm{K}^{+}$-ATPase & $\begin{array}{l}\text { Fungal } \\
\mathrm{H}^{+} \text {-ATPase }\end{array}$ & $\begin{array}{l}\text { Mitochondrial } \\
\mathrm{H}^{+} \text {-ATPase }\end{array}$ & $\begin{array}{l}\text { Vacuolar } \\
\mathrm{H}^{+} \text {-ATPase }\end{array}$ & $\begin{array}{l}\text { Bacterial } \\
\mathrm{H}^{+} \text {-ATPase }\end{array}$ \\
\hline Size (kDa) & 200 & 200 & $\sim 500$ & $\sim 500$ & $\sim 400$ \\
\hline Subunits & $\begin{array}{l}1 \\
\text { (dimer) }\end{array}$ & $\begin{array}{l}1 \\
\text { (dimer) }\end{array}$ & 8 & $5-10$ & $8-12$ \\
\hline Ion stimulation & $\mathrm{K}^{+}$ & - & - & $\because \mathrm{Cl}^{-}$ & - \\
\hline Electrogenic & $(-)$ & $1+1$ & $(+)$ & $(+)$ & $(+)$ \\
\hline \multirow[t]{4}{*}{ Inhibitors } & Vanadate & Vanadate & Oligomycin & NEM & $\mathrm{NO}_{3}^{-}$ \\
\hline & DCCD & DCCD & Azide & NBD-Cl & $\mathrm{NBD}-\mathrm{Cl}$ \\
\hline & & & Efrapeptin & $\mathrm{NO}_{3}^{-}$ & DCCD \\
\hline & & & DCCD & DCCD & \\
\hline
\end{tabular}


Table 2. Proton ATPases: subunit structure

\begin{tabular}{lll}
$\begin{array}{l}\text { Vacuolar } \\
\mathrm{H}^{*} \text {-ATPase }\end{array}$ & $\begin{array}{l}\text { Mitochondrial } \\
\mathrm{H}^{*} \text {-ATPase }\end{array}$ & $\begin{array}{l}\text { Archaebacterial } \\
\mathrm{H}^{+} \text {-ATPase }\end{array}$ \\
\hdashline Subunits (kDa) and stoichiometry (subscripts) \\
$? 100$ & \\
$\mathrm{~A}_{3} 70\left(\mathrm{C}^{*}\right)$ & $\alpha_{33} 55(\mathrm{R})$ & $\mathrm{A}_{3} 64(? \mathrm{R})$ \\
$\mathrm{B}_{33} 60(\mathrm{R})$ & $B_{3} 50(\mathrm{C})$ & $\mathrm{B}_{3} 54(? \mathrm{C})$ \\
$\mathrm{C} 41$ & $\because 31$ & $\mathrm{C} 28$ \\
$\mathrm{D} 34$ & $\delta 20$ & \\
E 33 & $\varepsilon 15$ & \\
Others & $\mathrm{a} 30$ & \\
$\mathrm{C}_{6} 16(\mathrm{PC})$ & $\mathrm{b}_{2} 17$ & $\mathrm{C} ? 10$ \\
\hline
\end{tabular}

* $\mathrm{C}=$ catalytic subunit : $\mathrm{R}=$ regulatory subunit : $\mathrm{PC}=$ probable proton channel.

Adapted from Table 1 . In: Nelson N, Taiz L. The evolution of $\mathrm{H}^{+}$-ATPases. Trends Biol Sci 1989; 14: 113-6.

vesicles have been purified sufficiently to allow identification of subunits and development of polyclonal and monoclonal anti-pump antibodies. The pump is a large structure with a molecular size reported to be $530-570 \mathrm{kDa}$ and it exhibits many striking structural similarities to the mitochondrial ATP synthase $\left(\mathrm{H}^{+}\right.$-ATPase $)$and to the cell membrane $\mathrm{H}^{+}$-ATPase of archaebacteria (Table 2) $[3,27,30]$. Four polypeptides in the range of 67-73, 56-60), 39-41 and 15-17 kDa have been described by six groups of investigators with a group of four to seven additional polypeptides in the ranges of 15-52 and 100-116 kDa reported by some workers. The stoichiometry (in parentheses) of these subunits has been reported by one laboratory to consist of $100(1)$, 73 (3), 58 (3), 40 (1), 38 (1), 34 (1), 33 (1), 19 (1), and $17 \mathrm{kDa}$ (6) ([3]). The mitochondrial ATP synthase is also a large multi-subunit enzyme with a similar number and size of subunits. Most investigators have identified ATP-protectable binding of N-ethylmaleimide (NEM) and NBD-Cl to the vacuolar $\mathrm{H}^{+}$-ATPase $67-73 \mathrm{kDa}$ polypeptide, and this has been termed the catalytic subunit. The 56-60 kDa subunit probably also binds ATP and, by analogy to the $\alpha$ subunit of the mitochondrial ATP synthase, has been proposed to be a regulatory subunit. The vacuolar $\mathrm{H}^{+}$-ATPase has multiple copies of a $15-17 \mathrm{kDa}$ subunit, which is also the site of DCCD binding. These subunits may form a transmembrane proton channel, similar to the channel formed by $6-12$ subunits of $8 \mathrm{kDa}$ in the mitochondrial $\mathrm{H}^{+}$-ATPase. Finally, most of the larger subunits are peripheral to the vesicle membrane on the cytoplasmic side and may form a large complex structure suggested to resemble the 'lollipop' structure of the mitochondrial ATP synthase. The exact structure and mechanism of the vacuolar $\mathrm{H}^{+}$ATPases, however, remains to be elucidated.

\section{Evolution of proton pumps}

Some of the vacuolar $\mathrm{H}^{+}$-ATPase subunits have been cloned, sequenced, and compared to other $\mathrm{H}^{+}$ATPases [3, 27, 31-35]. There is 60-70\% homology between the 70-kDa (catalytic) subunits of Neurospora and higher plants, $\sim 35 \%$ homology between the $70-\mathrm{kDa}$ subunit of plants and the catalytic subunit of mitochondria, 25\% homology between the 70- and 60-kDa subunits of Neurospora, and, interestingly, a similar degree of homology between the analogous $\beta$ and $\alpha$ subunits of mitochondria. Finally, the 17-kDa DCCD-binding subunit of yeast is very similar to the analogous subunit of the chromaffin granule $\mathrm{H}^{+}$-ATPase, and both are almost exactly twice the size of the DCCD-binding subunit of mitochondria. Based on these and other data. it has been suggested that all of the multisubunit $\mathrm{H}^{+}$-ATPases arose from a single ancestral cation pump in the cell membrane of an ancient single-celled organism that gave rise to archaebacteria, modern eubacteria, eukaryotic cells, and mitochondria and chloroplasts [28]. The vacuolar ATPase was, presumably, internalized by endocytosis of the cell's own plasma membrane (ATP binding site faces cytoplasm), whereas the mitochondrial $\mathrm{H}^{+}$. ATPase was internalized by eukaryotic cells through endocytosis of an ancestral bacteria (ATP binding site faces the mitochondrial matrix).

\section{Localization of the vacuolar $\mathrm{H}^{+}$-ATPase}

Although vacuolar $\mathrm{H}^{+}$-ATPases have been identified in many membranes by functional assays, only recently have antibodies to these purified $\mathrm{H}^{+}$-ATPases been developed and used to immunolocalize pumps in a few tissues. In corn root tip cells, immunogold particles decorate the limiting membrane of cell vacuoles and of Golgi apparatus. Antibodies to the renal $\mathrm{H}^{+}$-ATPase localize to the apical plasma membrane of epithelial cells in the proximal and distal convoluted tubules and to either apical or basolateral membranes of collecting duct intercalated cells; cells that may be specialized for either secretion of $\mathrm{H}^{+}$or of $\mathrm{HCO}_{3}^{-}[7,36,37]$. Finally, vesicles in amphibian bladder cells that are thought to contain proton 
pumps display, on the cytoplasmic face, arrays of closely packed stud-like particles that may represent the proton pumps.

\section{Roles of the vacuolar $\mathrm{H}^{+}$-ATPase}

The physiological roles of the vacuolar $\mathrm{H}^{+}$-ATPase are many and varied. Probably best understood is the role of vesicle acidification in facilitating the separation of ligands from receptors during receptormediated endocytosis of macromolecules such as low-density lipoproteins, serum proteins, immunoglobulins, hormones, etc. [1,2]. For many receptor-ligand pairs, binding affinity is higher at neutral $\mathrm{pH}$ (at the cell surface) and low at acidic $\mathrm{pH}$ (inside endosomes). After separation, many ligands are directed to lysosomes for degradation whereas receptors are returned (recycled) to the plasma membrane to undergo another cycle of endocytosis, If vesicles are alkalinized, receptor-mediated endocytosis is severely impaired. Vesicle acidification is also required for delivery of newly synthesized lysosomal enzymes to lysosomes, for lysosomal degradation of macromolecules, and for normal synthesis and secretion of some proteins.

Certain acidified vesicles also serve as storage compartments and a cytoplasm-to-vesicle-interior $\Delta \tilde{\mu}_{\mathrm{H}^{+}}$drives concentrative uptake of some solutes. The best-characterized example is catecholamine uptake and storage by adrenal chromaffin granules [38]. A specific reserpine-sensitive catechol/proton exchanger has been described in chromaffin granule membranes that uses the energy of the electrochemical proton gradient generated by the chromaffin granule $\mathrm{H}^{+}$-ATPase to drive concentrative uptake of catechols. Similar solute/proton antiporters have been described for calcium and for anions in plant vacuoles [39], and for arginine in Neurospora vacuoles. Preliminary work suggests that, in lysosomes, proton-coupled sugar and amino acid carriers may mediate efflux of these products of lysosomal degradation [40].

Finally, the 'vacuolar' $\mathrm{H}^{+}$-ATPase, or a very similar $\mathrm{H}^{+}$-ATPase, is found on the plasma membrane of some eukaryotic cells where it may mediate transepithelial $\mathrm{H}^{+} / \mathrm{HCO}_{3}{ }^{-}$transport such as in urinary acidification $[7,36,37]$, may help regulate intracellular $\mathrm{pH}$ [41], and may contribute to reabsorption of bone by osteoclasts. As work in this area continues, undoubtedly new roles for the vacuolar $\mathrm{H}^{+}$-ATPase will be uncovered.
In summary, much work over the past decade has provided considerable knowledge with regard to an important, unique, and widely distributed proton pump, the vacuolar $\mathrm{H}^{+}$-ATPase. Although much has been learned, many unanswered questions remain regarding the detailed structure, mechanism, regulation, location, and physiological role(s) of this proton pump.

\section{References}

1 Goldstein JL. Brown MS, Anderson RGW, Russell DW. Schneider WJ. Receptor-mediated endocytosis: concepts emerging from the LDL, receptor system. Ann Rev Cell Biol 1985: 1: 1-39.

2 Mellman I, Fuchs R. Helenius A. Acidification of the endocytic and exocytic pathways. Ann Rev Biochem 1986: 55 : 663-700.

3 Forgac M. Structure and function of the vacuolar class of ATPdriven proton pumps. Physiol Rev 1989; 69: 765-96.

4 Niederau C, Van Dyke R, Scharschmidt BF, Grendell JH. Rat pancreatic zymogen granules: an actively acidified compartment. Gastroenterology 1986: 91 : 1433-42.

5 Orci L. Ravazzola M. Amherdt M, Madsen O, Perrelet A. Vassalli J-D. Anderson RGW. Conversion of proinsulin to insulin occurs coordinately with acidification of maturing secretory vesicles. / Cell Biol 1986: 103: 2273-81.

6 Steinmetz P. Cellular organization of urinary acidification. Am J Physiol 1986; 251 : F173-87.

7 Brown D, Hirsch S, Gluck S. Localiyation of a proton-pumping ATPase in rat kidney. / Clin Invest 1988; 82: $2114-26$.

8 Stone DK. Xie X-S, Racker E. An ATP-driven proton pump in clathrin-coated vesicles. J Biol Chem 1983; 258: 4059-62.

9 Forgac M. Cantley L, Wiedenmann B, Altstiel L, Branton D. Clathrin-coated vesicles contain an ATP-dependent proton pump. Proc Natl Acad Sci, USA 1983; 80: 1300-3.

10) Van Dyke R, Steer CJ. Scharschmidt BF. Clathrin-coated vesicles from rat liver: enzymatic profile and characterization of ATP-dependent proton transport. Proc Natl Acad Sci, USA $1984 ; 81: 3108-12$.

11 Van Dyke R, Scharschmidt BF, Steer CJ. ATP-dependent proton transport by isolated brain clathrin-coated vesicles: role of clathrin and other determinants of acidification. Biochim Biophys Acta 1985: 812: 423-36.

12 Van Dyke R. Hornick CA. Belcher J. Scharschmidt BF. Havel RJ. Identification and characterization of ATP-dependent proton transport by rat liver multivesicular bodies. / Biol Chem 1985; 260: $11021-6$.

13 Fuchs R, Male P. Mellman I. Acidification and ion permeabilities of highly purified rat liver endosomes. I Biol Chem 1989; 264: 2212-20.

14 Ohkuma S. Moriyama. Y. Takano T. Identification and characterization of a proton pump on lysosomes by fluorescein isothiocyanate-dextran fuorescence. Proc Natl Acad Sci. USA $1982 ; 79: 2758-62$.

15 Harikumar P, Reeves JP. The lyososomal proton pump is electrogenic. I Biol Chem 1983; 258: 10403-10.

16 Moriyama Y. Nelson N. The purified ATPase from chromaffin granule membranes is an anion-dependent proton pump. I Biol Chem 1987: 262: 9175-80. 
17 Gluck S, Caldwell J. Immunoaffinity purification and characterization of vacuolar $\mathrm{H}^{+}$ATPase from bovine kidney. $J$ Biol Chem 1987; 262: 15780-9.

18 Van Dyke RW. Anion inhibition of the proton pump in rat liver multivesicular bodies. / Biol Chem 1986: 261: 15951-8.

19 Van Dyke R. Proton pump-generated electrochemical gradients in rat liver multivesicular bodies: quantitation and effects of chloride. I Biol Chem 1988: 263: 2603-11.

20) Pope AJ. Leigh RA. The use of a chloride-sensitive fluorescent probe to measure chloride transport in isolated tonoplast vesicles. Planta 1988: 176: 451-60.

21 Arai H. Pink S. Forgac M. Interaction of anions and ATP with the coated vesicle proton pump.. Biochemistry 1989; 28: $3075-82$.

$22 \mathrm{Xie}$ X-S. Stone DK. Isolation and reconstitution of the clathrincoated vesicle proton translocating complex. I Biol Chem 1986: $261: 2492-5$.

23 Cain CC. Sipe DM. Murphy RF. Regulation of endocytic pH by the $\mathrm{Na}^{\circ}, \mathrm{K}^{+}$-ATPase in living cells. Proc Natl Acad Sci. USA 1989: 86: 544-8.

24 Fuchs R, Schmid, S, Mellman I. A possible role for $\mathrm{Na}^{+}, \mathrm{K} \cdot$ ATPase in regulating ATP-dependent endosome acidification. Proc Natl Acad Sci. USA 1989; 86: 539-43.

25 Van Dyke RW. Matsumoto-Pon JK. Comparative function of proton pump in three types of rat liver endocytic vesicles. / Cell Biol 1988: 107: 809a.

26 Moriyama Y. Nelson N. Cold inactivation of vacuolar protonATPases. / Biol Chem 1989: 264: 3577-82.

27 Nelson $N$. The vacuolar proton-ATPase of eukaryotic cells. BioEssays 1987: 7: 251-4.

28 Nelson N. Taiz L. The evolution of $\mathrm{H}^{+}$-ATPases. Trends Biol Sci 1989: 14: 113-6.

29 Andersen OS, Silveira JEN. Steinmetz PR. Intrinsic characteristics of the proton pump in the luminal membrane of a tight urinary epithelium. J Gen Physiol 1985: 86:21 5-34.

30) Arai H. Terres G. Pink S, Forgac M. Topography and subunit stoichiometry of the coated vesicle proton pump. J Biol Chem 1988: 263: 8796-802.
31 Bowman EJ. Tenney K, Bowman BJ. Isolation of genes encoding the Neurospora vacuolar ATPase. I Biol Chem 1988: 263: 13994-14001.

32 Bowman BJ. Allen R. Wechser MA, Bowman EJ. Isolation of genes encoding the Neurospora vacuolar ATPase. I Biol Chem 1988: 263: 1400)2-7.

33 Hirsch S, Strauss A, Masood K. Lee S, Sukhatme V, Gluck S. Isolation and sequence of a cDNA clone encoding the $31-\mathrm{kDa}$ subunit of bovine kidney vacuolar $\mathrm{H}^{+}$-ATPase. Proc Natl Acad Sci. USA 1988: 85: 3004-8.

34 Mandel M. Moriyama Y. Hulmes JD, Pan Y-CE, Nelson H. Nelson N. cDNA sequence encoding the 16-kDa proteolipid of chromaffin granules implies gene duplication in the evolution of $\mathrm{H}^{+}$-ATPases. Proc Natl Acad Sci, USA 1988: 85: 5521-4.

35 Wang S-Y. Moriyama Y, Mandel $M$ et al. Cloning of cDNA encoding a 32-kDa protein. I Biol Chem 1988; 263: $17638-42$.

36 Brown D, Hirsch S. Gluck S. An $\mathrm{H}^{+}$-ATPase in opposite plasma membrane domains in kidney epithelial cell subpopulations. Nature 1988: 331: 622-4.

37 Schwartz GJ. Barasch J. Al-Awqati Q. Plasticity of functional epithelial polarity. Nature 1985: 318: 368-71.

38 Johnson RG Jr. Accumulation of biological amines into chromaffin granules: a model for hormone and neurotransmitter transport. Physiol Rev 1988; 68: 233-307.

39 Schumaker KS. Sze H. Decrease of $\mathrm{pH}$ gradients in tonoplast vesicles by $\mathrm{NO}_{3}$ and $\mathrm{Cl}$ : evidence for $\mathrm{H}^{+}$-coupled anion transport. Plant Physiol 1987: 83: 490-6.

40) Jonas AJ. Smith ML. Allison WS. Laikind PK, Greene AA. Schneider JA. Proton-translocating ATPase and lysosomal cystine transport. J Biol Chem 1983: 258: 11727-30.

41 Swallow CJ. Grinstein S. Rotstein OD. Cytoplasmic pH regulation in macrophages by an ATP-dependent and N.N'dicyclohexylcarbodiimide-sensitive mechanism. J Biol Chem 1988: 263: 19558-63.

Correspondence: Dr R. W. Van Dyke. Gastroenterology, 6520-D. MSRB-I. University of Michigan Medical Center, $1150 \mathrm{~W}$. Medical Center Drive, Ann Arbor. Michigan 48109-0682. USA. 